\title{
Neuro-linguistic Programming (NLP) for Language Teachers: Revalidation of an NLP Scale
}

\author{
Reza Pishghadam \\ Ferdowsi University of Mashhad, Iran \\ Shaghayegh Shayesteh \\ Ferdowsi University of Mashhad, Iran
}

\begin{abstract}
Enjoying much potential for learning and teaching, Neuro-linguistic programming (NLP) is regarded as a supplementary tool in $\mathrm{L} 2$ teaching and an approach to support learners to achieve excellence in their performance. Relying on its saliency, Pishghadam, Shayesteh, and Shapoori (2011) constructed and validated an NLP scale to examine the extent to which English language teachers employ NLP techniques in their practices. In accordance, this study attempted to revalidate the NLP scale through Rasch-rating scale model (RSM) and to underscore its importance in the field of language education. The WINSTEPS program was used to perform the Rasch measurement. Based on the analysis, items 5 and 9 were removed from the scale to maintain uni-dimensionality. To boot, given that the 5-category rating scale did not function satisfactorily, it was shifted to 3-category rating scale. At last, empirical findings were discussed, and implications were yielded in the context of English language teaching.
\end{abstract}

Index Terms-Neuro-linguistic programming (NLP), Rasch-rating scale model (RSM), revalidation, language education, NLP scale

\section{INTRODUCTION}

Today, working in education might seem to be a true challenge; given that, young learners manifest negative attitudes toward school and learning ever more. In response, teachers should be able to pacify the process and think up possible solutions to tackle the growing number of psycho-pedagogical issues (Pishghadam, 2011, Pishghadam \& Saboori, 2014). As with anything in life, effective relationship with learners is an indispensable module of every learning experience. NLP is now emerging as an emotional bridge which assists teachers to build and maintain functional rapport with students and motivate them throughout their learning journey toward success.

The term NLP, developed by Richard Bandler and John Grinder in 1970, broadly portrays people as a whole mindbody system with preset associations between neurological processes (neuro), language (linguistic) and learned behavioral strategies (programming) (Dilts, Grinder, Bandler, \& DeLozier, 1980). Indeed, NLP studies "brilliance and quality_ how outstanding individuals and organizations get their outstanding results” (O’Connor, 2001, p. 1).

Earlier studies of this humanistic approach were mainly psychotherapeutic-based, since NLP's initial inspiration rooted in the observation of adroit therapists Fritz Perls, the founder of Gestalt therapy, Virginia Satir, the family therapist, and Milton Erickson, the hypnotherapist (Tosey \& Mathison, 2010). Yet, gradually, therapists, counselors, sales persons, trainers, educators, and other practitioners of many kinds eagerly found this multi-disciplinary tool worthwhile to achieve efficacy in their area of expertise (Tosey, Mathison, \& Michelli, 2005; Zastrow, Dotson, \& Koch, 1987). More recent interest in practical view of NLP has arisen in the realm of education (Moore, 2009). Chief among them is the field of second/foreign language learning and teaching (Pishghadam, Shayesteh, \& Shapoori, 2011).

Nonetheless, despite its widespread popularity as a conceptual framework to effective communication, personal development, and learning, NLP has not been touched severely by the academic world. As criticized by Witkowski (2010) "today, after 35 years of research devoted to the concept, NLP reminds one more of an unstable house built on the sand rather than an edifice founded on the empirical rock" (p. 65). After all, believing in NLP's immense value not only in practice but also as a topic for research (Tosey \& Mathison, 2003) and observing the dearth of studies in this area, lately, Pishghadam, Shayesteh, and Shapoori (2011) gave a new dimension to the understanding of NLP pertinent to the field of English language learning and teaching. In so doing, they constructed and validated an NLP scale (via exploratory factor analysis) to investigate to what extent English language teachers incorporate NLP techniques in their teaching performance. Evaluating its association along with teacher's amount of success, experience, gender, and degree (Pishghadan, Shapoori, \& Shayesteh, 2011), they underlined NLP's absolute power in bringing up change within pedagogical settings. All the same, the attempt did not gain considerable recognition and was not conspicuous enough to the scholars of the field probably due to NLP's anti-theoretical status (Bandler \& Grinder, 1979), unclear evidence base, lack of evaluation of its practices (Tosey \& Mathison, 2010), or teachers' lack of relevant knowledge(Yero, 2001). 
Given these concerns, the current paper intends to revalidate the aforementioned scale and remind its saliency to L2 trainers, educators, and teachers anew.

\section{THEORETICAL BACKGROUND}

Ever since those early days, human beings have been seeking excellence in their lives and specifically in their communications as a constant goal. Relatively recent in origin, NLP, defined as 'the art of communication excellence', has attempted to maintain this very aim by showing interest in people, delving into their inner feelings and concentrating on how they think (Moore, 2009). Its remarkable application in developing rapport, influencing others, and changing behavior for the purpose of coping with life more effectively, can be accommodative.

As a tool of self-improvement NLP hinges on making complicated human behavior learnable by others through modeling excellence (Grinder, 1985). Its revolutionary principal, known as "modeling", basically revolves around Bateson's epistemological thinking notion on how we know the world (Tosey \& Mathison, 2010). Modeling, as the core process of NLP, investigates language patterns, behaviors and thoughts to uncover concealed cognitive strategies behind particular capabilities (Tosey \& Mathison, 2010).

In general, NLP is esteemed as the study of subjective experience stemming from individual's exclusive view of the world (Moore, 2009). That is, it shares constructivist's underlying principals by emphasizing idiosyncratic defined 'reality' (Craft, 2001). Based on this view, NLP downplays the role of social impact and heeds less to social dimensions caring for individual differences and uniqueness of their world interpretations (Toseyet al., 2005). Furthermore, its fundamental philosophy is encapsulated in the conceit the map is not the territory, meaning that individuals' reflections are based upon their confined internal representation of the world (map) and not the world itself (territory) (Grinder \& Bandler, 1976).

NLP is likewise recognized as a psychological vehicle for change assuming a drastic change to one's map of the world (Tosey et al., 2005). To improve communication and life quality, NLP presupposes a positive intention behind every single attitude. That is, it endeavors to elicit, reframe, and simply alter a negative intention or an unwanted behavior to a new positive pattern (Moore, 2009; Zastrow et al., 1987).

In essence, NLP appears to be further practical (technique driven) than theoretical (Heap 2008). Bandler and Grinder's (1979) interest in theory-in-use, what is useful rather than what is true, made them come up with an antitheoretical pragmatic method which goes beyond solid academic values and boundaries (Tosey \& Mathison, 2010). This leads several other scholars to regard NLP as a model rather than a theory of human behavior (Zastrow et al., 1987). To boot, its content embracing models, strategies, and techniques seem to be strongly eclectic (Tosey et al., 2005).

In numerous practical applications of NLP, education is ranked within the top. Among a broad range of techniques and frameworks offered by NLP, some specifically aim at teachers and learners (Beaver, 2002; Freeth, 2003; O'Connor $\&$ Seymour, 2000). This goal-oriented approach employs multiple techniques to generate enhanced performance in education. There seems to be much within NLP from which educators, teachers, and learners can avail. Yero (2001) and Tosey and Mathison (2003) underscore NLP's striking potentiality for teaching and learning. Building on his findings, Statham (2005) alleged that NLP can engender considerable improvements in learning and education. Moreover, Moore (2009) regarded NLP as a catalyst in fulfilling the needs of pedagogical systems. Kudliskis and Burden (2009) proposed NLP tactics as "given away" to teachers and students encountering exam anxiety and other germane pressures. Technically speaking, NLP could be taught to help improve memory, promote personal strength, adopt effective learning strategies, distinguish and reframe impeding educational beliefs, raise self-esteem, and optimize motivation (Dilts \& Epstein, 1995; Thornbury, 2001).

As a new horizon for language teachers and learners, NLP offers solutions to classroom problems (Tosey \& Mathison, 2003) and provides resources to accentuate language instruction (Helm, 2009; Millroad, 2004). Revell and Norman (1997) put forward 13 underlying NLP assumptions for language teachers to complement their belief system:

1. Mind and body are interdependent. Each impacts the other one.

2. The map is not the territory.

3. There is no failure.

4. The map becomes the territory. That is, what you consider to be true turns out to be true.

5. Be aware of what you want.

6. Our required resources are within us.

7. Communication is an amalgam of verbal and non-verbal behavior.

8. The unconscious mind is superior.

9. Communication in both conscious and unconscious.

10. There is a positive intention behind all behaviors.

11. The meaning of my communication is the response I receive.

12. Modeling excellent behavior leads to excellence.

13. Flexibility is a core component of the system.

NLP practitioners assume that on the condition language teachers adopt NLP techniques; their efficacy enhances (Antic, 2006). As a result of sundry teacher training workshops, Millroad (2004) reported that teachers' verbal 
interactions can influence English as a Foreign Language (EFL) learners' success or failure through establishing congruence by way of NLP strategies.

On the whole, to date, there is little empirical work into NLP scattered across different fields (Moore, 2009; Tosey \& Mathison, 2010). Generally speaking, teachers and educators focus their teaching chiefly on content regardless of teaching students the ways to master their minds. Therefore, the dire need for critical evaluation and research is palpable in this context. Eventually, the current paper sets out to draw scholars' attention and add further creditability and persuasion to the concept of integrating NLP in language education by revalidating the NLP scale already developed by Pishghadam, Shayesteh, and Shapoori (2011).

\section{MethodOLOGY}

\section{A. Participants}

Our community sample consisted of 154 English language teachers teaching at different private language institutes of Mashhad, Iran. They aged between 19 and 46 years old (Mean =21.7) with a range of between 1 and 23 years of teaching experience (Mean = 8.6). Our teachers were 91 females and 63 males who were majored in the various branches of English like English teaching, English literature, and English translation. It is necessary to mention that within the educational setting of Iran, people educated in different branches of English, with an adequate level of knowledge and proficiency in English language, are allowed to teach English (Pishghadam, Baghaei, \& Shayesteh). Therefore, holding EFL degree does not play a crucial role in recruiting teachers. The participants were selected based on their willingness to participate. Ethical approval was obtained prior to commencing the study and collecting data. Participants were initially informed that their identities would not be revealed and their responses would be kept confidential and used for the purpose of research only.

The rationale behind selecting language institutes and not public schools was the role of NLP in each setting. The educational policies within Iran's public schools are centralized. Decisions are made by the government and there exists less freedom on the part of the teachers to employ their materials and strategies including NLP techniques. In contrast, language institutes, adopt a de-centralized educational policy. That is, teachers have more freedom and flexibility in applying their own materials and skills. Moreover, relying on the fact that in public schools teachers are permanently employed, they do not have the fear of losing their jobs; hence, there remains no competition or interest for creating a more fruitful class (Pishghadam et al., 2012). On the contrary, institute teachers are temporarily employed. This indicates that on the condition they do not absorb more students to the institute; they will be replaced, shortly. Accordingly, teachers' enthusiasm rises alongside with their increased freedom and more efforts would be made to improve teacher-learner rapport by employing various approaches such as NLP techniques.

\section{B. Instrument}

The NLP scale utilized in this study for the purpose of revalidation was designed by Pishghadam, Shayesteh, and Shapoori (2011). The questionnaire comprises 38 items ranging from (5) "always" to (1) "never", requiring 20 minutes to complete. Factor analysis has been used to substantiate the construct validity of the scale, and its overall reliability has been $\mathrm{r}=.82$. This scale includes 8 factors: flexibility, anchoring, elicitation, modeling, individual differences, leading, establishing a rapport and emotional and cognitive boosters. Negatively worded items (i.e., 24, 33, 34, 36, 37, and 38) were reverse scored so that a total positively-oriented score can be achieved.

\section{Procedure}

The data was entered into and processed with WINSTEPS software (Linacre, 2009). Rasch rating scale model (RSM) (Andrich, 1987) was employed for revalidation. Initially, fit indices were calculated to find out whether the data fulfill the logistic model assumptions. Thereafter, category functioning was examined to recognize if the 5-category rating scale was a proper choice. The purpose behind selecting RSM as the proper measurement tool was the potential merits of this relatively new theory over the classical test theory (CTT):

1. RSM rejects the concept of raw scores and provides person and item estimates that are placed on an interval scale.

2. RSM is item and person free; that is, it yields estimates for item difficulty and person abilities separately, yet on a common interval scale. On the contrary, CTT is test and sample dependent, it means the item difficulties depend on the samples general ability (Ferreira, Almeida, \& Prieto, 2011). To be specific, focusing on individual items and persons rather than on group statistics, RSM predicts how persons with given underlying ability levels are expected to endorse each item (Conrad \& Smith, 2004).

\section{RESUlts}

In order to substantiate the construct validity of the scale fit indices together with category statistics were studied through the lens of RSM (Andrich, 1987) as applied in the software program WINSTEPS (Linacre, 2009).

\section{A. Fit Indices}

The preliminary analysis of all the 38 items yielded an item separation index of 2.66 with an item reliability of 0.88 (see Table 1), and a person separation index of 2.23 (see Table 2) with a person reliability of 0.83 . 
TABLE 1:

SUMMARY OF 38 MEASURED ITEM

\begin{tabular}{|c|c|c|c|c|c|c|c|c|}
\hline & \multirow{2}{*}{ TOTAL SCORE } & \multirow{2}{*}{ COUNT } & \multirow{2}{*}{ MEASURE } & \multirow{2}{*}{ MODEL ERROR } & \multicolumn{2}{|l|}{ INFIT } & \multicolumn{2}{|c|}{ OUTFIT } \\
\hline & & & & & MNSQ & ZSTD & MNSQ & ZSTD \\
\hline MEAN & 552.1 & 154.0 & .00 & .07 & 1.06 & .0 & 1.07 & .2 \\
\hline S.D. & 44.2 & .0 & .19 & .01 & .32 & 2.3 & .31 & 2.0 \\
\hline MAX. & 631.0 & 154.0 & .36 & .08 & 2.11 & 5.3 & 2.05 & 5.1 \\
\hline MIN. & 453.0 & 154.0 & -.40 & .05 & .54 & -5.0 & .56 & -4.2 \\
\hline \multicolumn{2}{|c|}{ REAL RMSE } & \multirow{2}{*}{\multicolumn{2}{|c|}{ TRUE SD }} & $\begin{array}{ll}\text { SEPARATION } 2.40 \\
\end{array}$ & \multicolumn{4}{|c|}{$\begin{array}{ll}\text { ITEM RELIABILITY } & .85\end{array}$} \\
\hline \multicolumn{2}{|c|}{$\begin{array}{ll}\text { MODEL RMSE } & .07\end{array}$} & & .18 & $\begin{array}{l}\text { SEPARATION } 2.66 \\
\end{array}$ & \multicolumn{4}{|c|}{$\begin{array}{ll}\text { ITEM RELIABILITY } & .88\end{array}$} \\
\hline
\end{tabular}

The fourth column, "MEASURE", indicates item difficulty; that is, bigger values signify more difficult items. "MODEL ERROR", the third column, displays the standard error of the item difficulty estimates. In this table, item measures range from .36 (i.e., "I correct all the learners' errors") to -0.40 (i.e., "I show my interest in the topics presented by my students") logits. The root mean square error (RMSE) is 0.7 for items and is 0.14 for persons, suggesting an accurate measurement.

TABLE 2:

SUMMARY OF 154 MEASURED PERSON

\begin{tabular}{|c|c|c|c|c|c|c|c|c|}
\hline & \multirow[b]{2}{*}{ TOTAL SCORE } & \multirow[b]{2}{*}{ COUNT } & \multirow[b]{2}{*}{ MEASURE } & \multirow[b]{2}{*}{ MODEL ERROR } & \multicolumn{2}{|l|}{ INFIT } & \multicolumn{2}{|c|}{ OUTFIT } \\
\hline & & & & & MNSQ & ZSTD & MNSQ & ZSTD \\
\hline MEAN & 136.2 & 38.0 & .44 & .14 & 1.03 & -.1 & 1.07 & .1 \\
\hline S.D. & 17.1 & .0 & .35 & .03 & .44 & 1.8 & .47 & 1.7 \\
\hline MAX. & 179.0 & 38.0 & 1.99 & .31 & 2.19 & 3.6 & 2.55 & 3.4 \\
\hline MIN. & 75.0 & 38.0 & -.35 & .10 & .21 & -4.9 & .21 & -4.6 \\
\hline \multicolumn{2}{|c|}{ REAL RMSE } & \multicolumn{2}{|c|}{ TRUE SD .31} & SEPARATION 1.97 & \multicolumn{4}{|c|}{$\begin{array}{ll}\text { PERSON RELIABILITY } & .89\end{array}$} \\
\hline \multicolumn{2}{|c|}{$\begin{array}{ll}\text { MODEL RMSE } & .14 \\
\end{array}$} & \multicolumn{2}{|c|}{$\begin{array}{ll}\text { TRUE SD } & .32 \\
\end{array}$} & $\begin{array}{ll}\text { SEPARATION } & 2.23 \\
\end{array}$ & \multicolumn{4}{|c|}{ PERSON RELIABILITY } \\
\hline
\end{tabular}

Table 3 revealed that a couple of items did not fulfill the model expectations implying that they would possibly measure a construct that is far from the rest of the items or present a further dimension. Based on the table, items 5 and 9 widely misfit the model building upon the criteria set forth by Wright and Linacre (1994) for rating scale data (Infit MNSQ 0.6 to 1.4). In principle, misfit items holding infit MNSQ smaller than 0.6 indicate overfit or redundancy but do not impair the construct validity of the scale. Conversely, items with MNSQ estimates greater than 1.4 diverge from the measurement of the targeted construct and deteriorate the analysis (Linacre, 2005). Thus, in order to improve the model fit, items 5 and 9 were removed from the measurement relying on the fact that they might entail a distinct dimension and lead to multidimensionality. 
TABLE 3:

ITEM STATISTICS AND FIT STATISTICS

\begin{tabular}{|c|c|c|c|c|}
\hline ENTRY NUMBER & MEASURE & MODEL S.E. & INFIT MNSQ & ITEM \\
\hline 34 & .36 & .05 & .76 & NLP 34 \\
\hline 25 & .33 & .06 & .71 & NLP 25 \\
\hline 35 & .27 & .06 & .71 & NLP 35 \\
\hline 37 & .22 & .06 & .90 & NLP 37 \\
\hline 36 & .21 & .06 & .70 & NLP 36 \\
\hline 31 & .19 & .06 & .78 & NLP 31 \\
\hline 3 & .19 & .06 & .76 & NLP 3 \\
\hline 22 & .18 & .06 & .72 & NLP 22 \\
\hline 10 & .18 & .06 & 1.06 & NLP 10 \\
\hline 23 & .18 & .06 & .74 & NLP 23 \\
\hline 33 & .16 & .06 & .76 & NLP 33 \\
\hline 6 & .14 & .06 & .77 & NLP 6 \\
\hline 15 & .14 & .06 & .72 & NLP 15 \\
\hline 7 & .09 & .06 & 1.15 & NLP 7 \\
\hline 8 & .03 & .06 & 1.39 & NLP 8 \\
\hline 20 & .02 & .06 & .73 & NLP 20 \\
\hline 21 & .00 & .07 & .81 & NLP 21 \\
\hline 16 & .00 & .07 & 1.39 & NLP 16 \\
\hline 11 & -.01 & .07 & 1.23 & NLP 11 \\
\hline 32 & -.01 & .07 & .87 & NLP 32 \\
\hline 17 & -.02 & .07 & 1.05 & NLP 17 \\
\hline 19 & -.03 & .07 & .74 & NLP 19 \\
\hline 30 & -.05 & .07 & 1.30 & NLP 30 \\
\hline 13 & -.06 & .07 & .94 & NLP 13 \\
\hline 4 & -.06 & .07 & 1.12 & NLP 4 \\
\hline 9 & -.07 & .07 & 1.47 & NLP 9 \\
\hline 28 & -.07 & .07 & 1.30 & NLP 28 \\
\hline 29 & -.07 & .07 & 1.23 & NLP 29 \\
\hline 18 & -.13 & .07 & 1.27 & NLP 18 \\
\hline 24 & -.15 & .07 & .72 & NLP 24 \\
\hline 12 & -.16 & .07 & 1.29 & NLP 12 \\
\hline 27 & -.19 & .07 & 1.14 & NLP 27 \\
\hline 38 & -.20 & .07 & 1.22 & NLP 38 \\
\hline 26 & -.24 & .08 & 1.16 & NLP 26 \\
\hline 5 & -.30 & .08 & 2.11 & NLP 5 \\
\hline 14 & -.32 & .08 & 1.27 & NLP 14 \\
\hline 2 & -.34 & .08 & 1.12 & NLP 2 \\
\hline 1 & -.40 & .08 & .91 & NLP 1 \\
\hline MEAN & .00 & .07 & 1.06 & \\
\hline S.D. & .19 & .01 & .32 & \\
\hline
\end{tabular}

The first misfitting item is Item 5 ("when the learners do not understand something, I present it in a new way") with infit MNSQ of 2.11. The second misfitting item is Item 9 ("to ensure learners' understanding and to remove the ambiguities I ask them some questions") with the fit MNSQ of 1.47. These items are indicators of multidimensionality and therefore must be removed from the scale. 


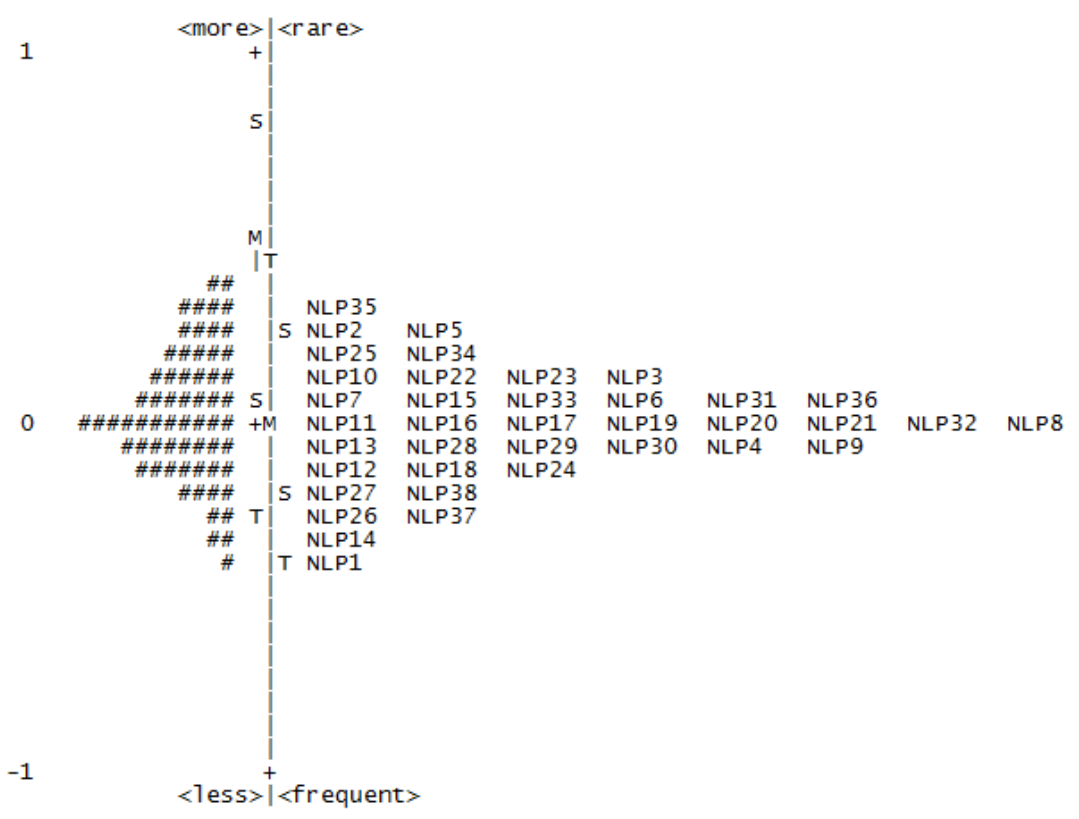

Fig 1. Items-persons map

The items-persons map in Figure1 above illustrates that the construct represented by the items is well covered by the scale. As the figure suggests, items are spread all over the scale which implies that they cover a wide range of the NLP constructs. Moreover, the majority of the thresholds have clustered towards the center of the scale, which indicates that the scale is a precise measurement of the construct and well-targeted for the sample.

\section{B. Category Functioning}

As previously noted, our sample respondents displayed their degree of agreeability based on a 5-point Likert type scale. Relying on Table 4 Rating Scale Statistics, "CATEGORY LABEL" shows the label of each category (i.e., strongly disagree to strongly agree), and "OBSERVED COUNT" explicates the number of times each single category is rated. The "OBSERVED AVERAGE" advances alongside with category values. That is to say, as the participants' abilities increase, the probability of rating category 5 enhances accordingly. "Infit MNSQ" and "Outfit MNSQ" consider the average of infit and outfit mean-squares of the responses to each single category. Based on Table 4, fit indices are totally placed within the safe area (0.6 to 1.4$)$.

TABLE 4:

RATING SCALE STATISTICS (12345)

\begin{tabular}{|l|l|l|l|l|l|l|}
\hline $\begin{array}{l}\text { CATEGORY } \\
\text { LABEL }\end{array}$ & $\begin{array}{l}\text { OBSERVED } \\
\text { COUNT }\end{array}$ & $\begin{array}{l}\text { OBSEREVED } \\
\text { AVERAGE }\end{array}$ & $\begin{array}{l}\text { INFIT } \\
\text { MNSQ }\end{array}$ & $\begin{array}{l}\text { OUTFIT } \\
\text { MNSQ }\end{array}$ & $\begin{array}{l}\text { STRUCTURE } \\
\text { CALIBRATION }\end{array}$ & $\begin{array}{l}\text { CATEGORY } \\
\text { MEASURE }\end{array}$ \\
\hline 1 & 311 & .24 & 1.05 & 1.31 & NONE & $(-1.32)$ \\
\hline 2 & 390 & .24 & .87 & .99 & .09 & -.43 \\
\hline 3 & 1338 & .31 & .98 & .90 & -1.01 & .04 \\
\hline 4 & 1634 & .45 & .87 & .32 & .00 & .76 \\
\hline 5 & 2234 & .67 & .65 & .88 & .54 & $(2.12)$ \\
\hline
\end{tabular}

"STRUCTURE CALIBRATION" or Rasch-Andrich thresholds are regarded as the points at which either of the two adjacent categories may be equally rated (Linacre 2005). Since, the first category is not preceded by any other category; it has no estimate and is presented as "NONE". From this perspective, positive values suggest that the lower of the two adjacent categories is more probable to be rated; while, negative values indicate that the higher category is more likely to be observed. The empirical ordering of the categories which increase along the continuum is a fundamental prerequisite to Rasch measurement. The step calibration value for categories $2(0.05), 3(-1.18)$ and 4 (.00) broadly damage the measurement's monotonically increasing trend. As a matter of fact, step calibration disorder entails that either the category structure is too narrow to distinguish, or too many alternatives have been selected (Linacre, 1999). Moreover, the distance between the thresholds should not surpass 5 logits to prevent data loss owing to the absence of suitable categories, or fall below 1.4 logits to explain the distinctiveness of the categories (Linacre, 1999). Thus, it is deduced that our respondents were not capable of making a distinction between the steps and gestate the five levels of performance accurately; as a result, the 5-categories did not yield consistent outcomes.

To preserve the category chain and enhance fit to the model, a number of configurations encompassing three and four category scales were examined. Nonetheless, the 12223 pattern engendered the best indices. In consequence, the 
adjacent categories 2, 3 and 4 were integrated into 2 and the 12345 category pattern (5-point scale) was shifted to 12223 (3-point scale) (Table 5).

TABLE 5:

RATING SCALE STATISTICS (12223)

\begin{tabular}{|l|l|l|l|l|l|l|}
\hline $\begin{array}{l}\text { CATEGORY } \\
\text { LABEL }\end{array}$ & $\begin{array}{l}\text { OBSERVED } \\
\text { COUNT }\end{array}$ & $\begin{array}{l}\text { OBSEREVED } \\
\text { AVERAGE }\end{array}$ & $\begin{array}{l}\text { INFIT } \\
\text { MNSQ }\end{array}$ & $\begin{array}{l}\text { OUTFIT } \\
\text { MNSQ }\end{array}$ & $\begin{array}{l}\text { STRUCTURE } \\
\text { CALIBRATION }\end{array}$ & $\begin{array}{l}\text { CATEGORY } \\
\text { MEASURE }\end{array}$ \\
\hline 1 & 675 & .19 & 1.25 & 1.14 & NONE & $(-2.84)$ \\
\hline 2 & 1438 & .41 & .89 & .90 & .67 & 1.3 \\
\hline 3 & 2241 & .79 & .93 & .94 & .99 & $(2.78)$ \\
\hline
\end{tabular}

Table 5 reports that the overall rating scale statistics operate satisfactorily after collapsing categories. The observed average and structure calibration statistically advance along with category values. Moreover, the threshold estimates in addition to mean square fit indices are located within the acceptable range of 1.4 to 5 and 0.6 to 1.4 , respectively.

\section{DISCUSSION}

Paying greater attention to providing better inner and external learning environments and using sensory rich language may cause students to learn more effectively and teachers to teach more easily. By recognizing better learning strategies using NLP techniques, teachers are able to open up their students' minds to greater possibilities and more opportunities in life. To meet this end, the current study intends to revalidate the NLP scale constructed and validated by Pishghadam, Shayesteh, and Shapoori (2011) with the purpose to measure the extent to which English language teachers employ NLP techniques in their classes. To revalidate the 38-item NLP scale, Rasch rating scale model (Andrich, 1987) was employed.

The results of the Rasch measurement indicated that except for items 5 and 9, the remaining items operated well within the model. To achieve satisfactory fit, it was necessary to remove the misfitting items. Item 5 is "When the learners do not understand something, I present it in a new way". Being flexible and esteeming students' individual differences are core components of NLP (Revell \& Norman, 1997). However, the relevance of the item to the concept of NLP is ignored in the context of language learning in Iran. The likely justification may be that, due to the institutes' compact syllabuses and heavy teaching loads, teachers hardly find time to re-present the materials in a different way. As an extension to the issue, paying attention to individual differences is valued by the teachers (i.e., considering students' language abilities 'item 4', eye movement 'item 8' and opinions 'item 27'); yet, is not feasible and practical at times owing to some contextual barriers.

Item 9 is "To ensure learners' understanding and to remove the ambiguities I ask them some questions". As the item implies, our teachers probably adopt further strategies, apart from asking questions and elicitation, to assure their learners' full understanding. Indeed, teachers might notice the issue by directly observing students' non-verbal behaviors rather than the verbal ones (Pishghadam, Shayesteh, \& Shapoori, 2011). This also supports Revell and Norman's (1997) assumption of emphasizing both verbal and non-verbal communication.

Based on the results gained from the category measurements, the 5-category structure (12345) which was selected in the first place, did not operate productively for the NLP scale. Subsequent to inspecting a number of configurations, 3category structure (234) witnessed to be a better option. Consequently, for the purpose of sustaining distinctiveness, choices 1 (strongly disagree), and 5 (strongly agree) were removed and the rating pattern shifted to: 2 (disagree), 3 (undecided) and 4 (agree).

The analysis manifested the hierarchy of NLP strategies employed by our sample EFL teachers. The most difficult item was found to be item 34 "I correct all the learners' errors". In truth, the hardest item is practiced less in the classrooms. That is to say, teachers generally do not correct all learners' errors. From NLP perspective, there is a positive intention behind all behaviors (Revell \& Norman, 1997; Zastrow et al., 1987). Therefore, students' mistakes and errors are viewed as integral parts of language learning classes (Brown, 2007). In this regard, teachers resist the tendency to correct every single error and create a positive climate which encourages learners to talk (Chastain, 1988). On the other hand, the easiest item was found to be item 1 "I show my interest in the topics presented by my students". The teachers broadly apply this NLP technique in their classes and regard students' viewpoints. Supporting Bandler and Grinder's (2005) idea of establishing a rapport, teachers attempt to maintain better attraction and involvement in the students by welcoming their proposed topics.

The value of this study resides in revalidating the NLP scale which can be a striking merit to researchers interested in studying NLP and language school managers in recruiting eligible teachers who are able to build effective rapport with their students. By employing NLP techniques and identifying their undeniable role in the educational domain, the teachers can cultivate their ultimate capabilities and emotionally attract more students to classroom environment (Pishghadam, Shayesteh, and Shapoori 2011).

On the whole, to buttress and promote the current instrument, it is suggested to replicate the study with a larger and more appropriate sample. Besides, further studies can be carried out employing this NLP scale to discover its likely correlation with distinct pedagogical and psychological variables. Another potential research can concentrate on ways to raise teachers' inclinations toward administering more NLP techniques in classroom area. 
Last but not least, the researchers faced different limitations throughout this study. Due to restricted sampling, universal generalization of the outcome is slightly problematic; however, similar contexts and samples may better benefit from the implications. Moreover, the current NLP scale is a self-report. In truth, advertently or inadvertently participants may not submit accurate answers in order to look better or hide their actual self. Accordingly, potential bias threatens its validity (Baer, 1998). In the end, since our sample teachers were majored in different branches of English (i.e., English teaching, English literature and English translation) further research is recommended to investigate teachers' views majored in English teaching (TEFL) who have gone through the pertinent university courses and are more acquainted with the nature of educational psychology and NLP.

\section{APPENDIX}

Neuro-linguistic Programming Questionnaire

1. I show my interest to the topics presented by my students.

2. In answering the questions, I give hints to the students.

3. While teaching, I use some of the words or phrases used by the learners.

4. I help my students with less ability.

5. When the learners do not understand something, I present it in a new way.

6. I ask my students to pay attention to similarities and differences of the subjects.

7. I give my students the words needed for a conversation.

8. I pay attention to the language learners' eye movements.

9. To ensure learners' understanding and to remove the ambiguities, I ask them some questions.

10. I let the learners move freely in the classroom.

11. I give enough time to the language learners to write down notes and do class activities.

12. I try to create a positive feeling in my students toward language learning.

13. I create new challenges for my students.

14. When the language learners do not understand a subject matter, I write it down on the board.

15. If needed, I ask the language learners to speak clearly.

16. For holding a dialogue, I present the required grammar.

17. I prefer to call my students by their first name.

18. I welcome new and creative answers.

19. I make use of flash cards, CDs, posters, and other teaching aids.

20. I ask my students to pay attention to details.

21. I pay attention to individual differences.

22. I talk about myself and my own experiences in the classroom.

23. I ask my students of my teaching and speaking rate in the classroom.

24. I make use of only one teaching method.

25. I assign a special duty for every individual.

26. During the teaching process, I write down the new material on the board.

27. All my students' opinions are important to me.

28. I get my students' ideas of the topics presented in the class.

29. For better learning and understanding, I ask the learners to take notes.

30. I write down the new subject material on the board as a model.

31. I inform my students of their progress.

32. I give feedback to my students' correct and incorrect answers.

33. I run the class in a formal way.

34. I correct all the language learners' errors.

35. I ask successful language learners to talk about their personal ways of progress in the classroom.

36. I expect my students to adjust themselves to my teaching rate.

37. The learners can form groups freely.

38. I do not make use of encouragement for my students' progress.

\section{REFERENCES}

[1] Antic, Z. (2006). Neuro-linguistic programming- The link between medicine (neurology) and language teaching. Medicine and Biology, 13(2), 123-126.

[2] Baer, J. (1998). The case for domain specificity of creativity. Creativity Research Journal, 11(2), 173-177.

[3] Bandler, R., \& Grinder, J. (1979). Frogs into princes. Moab, UT: Real People Press.

[4] Beaver, D. (2002). NLP for lazy learning: How to learn faster and more effectively. London: Vega Books.

[5] Brown, H. D. (2007). Principles of language learning and teaching ( $5^{\text {th }}$ ed.). White Plains, NY: Pearson Education.

[6] Chastain, K. (1988). Developing second language skills: Theory and practice ( $3^{\text {rd }}$ ed.). San Diego: Harcourt Brace Jovanovich.

[7] Conrad, K. J., \& Smith, E. V. (2004). International conference on objective measurement: Applications of Rasch analysis in health care. Medical Care, 42(1), 1-6. 
[8] Craft, A. (2001). Neuro-linguistic programming and learning theory. The Curriculum Journal, 12(1), 125-136.

[9] Dilts, R., \& Epstein, T. (1995). Dynamic learning, Meta Publications Inc., California

[10] Dilts, R., Grinder, J., Bandler, R., \& DeLozier, J. (1980). Neuro-linguistic programming: The study of the structure of subjective experience (Vol. 1). Capitola, CA: Meta Publications.

[11] Freeth, P. (2003). NLP-skills for learning: A practical handbook for increasing learning potential. Oxford, UK: Communications in Action.

[12] Frreira, A. I., Almeida, L. S., \& Prieto, G. (2011). The role of processes and contents in human memory: An item response theory approach. Journal of Cognitive Psychology, 23(7), 873-885.

[13] Grinder, J., \& Bandler, R. (1976). The structure of magic II. Palo Alto, California: Science and Behavior Books.

[14] Heap, M. (2008). The validity of some early claims of neuro-linguistic programming. Skeptical Intelligencer, 11, 1-8.

[15] Helm, D. J. (2009). Improving English instruction through neuro-linguistic programming. Education, 130(1), 110-113.

[16] Kudliskis, V., \& Burden, R. (2009). Applying 'what works' in psychology to enhancing examination success in schools: The potential contribution of NLP. Thinking Skills and Creativity, 4(3), 170-177.

[17] Linacre, J. M. (1999). Category disordering vs. step (threshold) disordering. Rash Measurement Transactions, $13(1)$, 675. Available: http://www.rasch.org/rmt/rmt131a.htm.

[18] Linacre, J. M. (2005). A user's guide to WINSTEPS. Chicago, IL: Mesa Press.

[19] Linacre, J. M. (2009). WINSTEPS Rasch programme. Version 3.63.0.

[20] Millroad, R. (2004). The role of NLP in teachers' classroom discourse. ELT Journal, 58(1), 28-37.

[21] Moore, C. (2009). NLP in education. Unpublished M.Sc. thesis, Nui Maynooth University, Ireland.

[22] O'Connor, J. (2001). NLP workbook. A practical guide book to achieving the results you want. London: HarperCollins.

[23] O'Connor, J., \& Seymour, J. (2000). Training with NLP. London: HarperCollins.

[24] Pishghadam, R. (2011). Introducing applied ELT as a new approach in second/foreign language studies. Iranian EFL Journal, 7(2), 8-14.

[25] Pishghadam, R., Baghaei, P. Shayesteh, S. (2012). Construction and validation of an English language teacher creativity scale (ELT-CS). Journal of American Science, 8(3), 497-508.

[26] Pishghadam, R. \& Saboori, F. (2014). A socio-cultural study of language teacher status. International Journal of Society, Culture \& Language, 2(1), 63-72.

[27] Pishghadam, R., Shapoori, M., \& Shayesteh, S. (2011). NLP and its relationship with teacher success, gender, teaching experience and degree: A comparative study. World Journal of English Language, 1(2), 2-8.

[28] Pishghadam, R., Shayesteh, S., \& Shapoori, M. (2011). Validation of an NLP scale and its relationship with teacher success in high schools. Journal of Language Teaching and Research, 2(4), 909-917.

[29] Revell, J., \& Norman, S. (1999). Handing over: NLP-based activities for language learning. London: Saffire Press.

[30] Richards, J. C., \& Rodgers, T. S. (2001). Approaches and methods in language teaching. New York: Cambridge University Press.

[31] Thornbury, S. (2001). The unbearable lightness of EFL. ELT Journal, 55(4), 391-402.

[32] Tosey, P., \& Mathison, J. (2003). Neuro-linguistic programming and learning theory: A response. Curriculum Journal, 14, 371-388.

[33] Tosey, P., \& Mathison, J. (2010). Neuro-linguistic programming as an innovation in education and teaching. Innovations in Education and Teaching International, 47(3), 317-326

[34] Tosey, P., Mathison, J., \& Michelli, D. (2005). Mapping transformative learning: The potential of neuro-linguistic programming. Journal of Transformative Education, 3, 140-167,

[35] Witkowski, T. (2010). Thirty five years of research on neuro-linguistic programming. NLP research data base. State of the art or pseudoscientific decoration? Polish Psychological Bulletin, 41(2), 58-66.

[36] Yero, J. L. (2001). NLP and education: A shift of focus. Anchor Point Magazine, 15(9), 37-41.

[37] Zastrow, C., Dotson, V., \& Koch, M. (1987). The neuro-linguistic programming treatment approach. Journal of Independent Social Work, 1(1), 29-38.

Reza Pishghadam has a PhD in Teaching English as a Foreign Language (TEFL). He is currently on the English faculty of Ferdowsi University of Mashhad, Iran. He is now an associate professor of TEFL, who teaches socio-psychological aspects of language education. Over the last five years, he has published more than 120 articles and books in different domains of English language education. In 2007, he was selected to become a member of the National Association of Elites of Iran. In 2010, he was classified as the distinguished researcher in humanities by the Ministry of Sciences, Research, and Technology of Iran. His current research interests are: psychology and sociology of language education, cultural studies, syllabus design, and language testing.

Shaghayegh Shayesteh has an MA in TEFL from Ferdowsi University of Mashhad, Iran. She has published several articles in national and international journals. Her current research interests are psychology and sociology of language education. 